\title{
THE SYSTEMATIC POSITION OF PAPPOCETUS LUGARDI AND A NEW TAXON FROM NORTH AMERICA (ARCHAEOCETI: PROTOCETIDAE).
}

McLEOD*, Samuel A., Section of Vertebrate Paleontology, Natural History Museum of Los Angeles County, 900 Exposition Boulevard, Los Angeles, California, 90007, U.S.A.; BARNES, Lawrence G., Section of Vertebrate Paleontology, Natural History Museum of Los Angeles County, 900 Exposition Boulevard, Los Angeles, California, 90007, U.S.A.

The derived protocetid archaeocete Pappocetus lugardi Andrews, 1920, is a medium-sized archaeocete that probably attained a body length of approximately 3 to $4 \mathrm{~m}$ when alive. It is known only from the Middle Eocene Ameki Formation of Nigeria. Both the holotype and paratype mandibles represent subadult animals with incomplete eruption of the posterior molars. Further cleaning of the holotype specimen reveals that it was broken and offset in the symphyseal area and this offset has hampered previous interpretations of the mandibular morphology. Likewise, further preparation of the paratype specimen reveals additional information about the mandibular morphology, particularly in regards to the position and eruption of the teeth.

A related taxon, a new genus and species, is represented by fossils from Middle and Late Eocene deposits in the Atlantic Coastal Plain of North and South Carolina. The most complete specimen consists of two partial dentaries of one individual, with teeth. Other isolated teeth represent the same species. This is the first record of a Pappocetus-like animal from the new world, and is the first named species of protocetid from the western North Atlantic. Younger and more derived species of archaeocetes, placed in the family Basilosauridae, have long been known from deposits in the Gulf Coastal Plain of the United States and in the Fayum region of Egypt.

Pappocetus and the new genus can be distinguished from other protocetids at the subfamily level. Furthermore, certain characteristics of the pappocetine teeth are retained in basilosaurid archaeocetes, indicating the affinities between the protocetid and basilosaurid archaeocetes. 